EVANESCENCIAS EN LAS TRADUCCIONES DEL CHILAM BALAM DE CHUMAYEL: EL MAÍZ Y EL FRIJOL DEL SUR, LOS IBES DEL ORIENTE Y EL POZOL RITUAL EVANESCENCE IN TRANSLATIONS FROM CHILAM BALAM OF CHUMAYEL: MAIZE AND BEANS FROM THE SOUTH, LIMA BEANS FROM THE EAST, AND RITUAL POZOL

\author{
Miguel VASSALLo Rodríguez \\ Maestría en Estudios Mesoamericanos, Universidad Nacional Autónoma de México \\ e Instituto de Liderazgo en Artistas
}

\begin{abstract}
Resumen: Este trabajo intenta devolverle a las traducciones del maya el sentido original de algunos párrafos de la primera página del Chilam Balam de Chumayel, que fueron alterados en diversas ediciones de este libro. Los parágrafos contenidos al inicio del texto reflejan la concepción de que al comienzo de esta era los elementos del axis mundi se desdoblaron en los cuadrantes del cosmos, replicándose pero adquiriendo el color y ciertas características inherentes a cada uno de los cuatro rumbos del cosmos. Algunas traducciones y ediciones omitieron al maíz y/o al frijol del rumbo Sur y a los ibes del Oriente, lo que mutila el sentido general de esa parte del texto original, donde dichos elementos están indubitablemente presentes. También se busca restituir la presencia del pozol ritual (saka') y del tzune en dos de las interrogantes de Zuyua than, elementos erróneamente identificados como "atole" en todas las ediciones del Chumayel.
\end{abstract}

Palabras clave: Chilam Balam, rumbos del cosmos, maíz, pozol, tzune.

ABSTRACT: This paper is an attempt to restitute the original meaning of Maya translations of some paragraphs contained in the first page of the Chilam Balam of Chumayel. The verses contained at the initial section of the Maya text show the cosmological conception associated with the beginnings of this era, when the elements of the Axis mundi split into four directions. Some translations and editions omit the mention of maize and/or beans in the south and the lima beans in the east; this omission mutilates the complete meaning of this part of the text, where they are evidently present. I also attempt to restitute the presence of ritual pozol (saka') and tzune in two of the Zuyua than interrogations, where they were misidentified as atole in all the Chumayel editions.

KeYwords: Chilam Balam, cosmic directions, maize, pozol, tzune.

ReCEPCIÓN: 16 de agosto de 2015.

ACEPTADO: 23 de octubre de 2015. 



\title{
EVANESCENCIAS EN LAS TRADUCCIONES DEL CHILAM BALAM DE CHUMAYEL: EL MAÍZ Y EL FRIJOL DEL SUR, LOS IBES DEL ORIENTE Y EL POZOL RITUAL
}

\author{
Miguel Vassallo Rodríguez \\ Maestría en Estudios Mesoamericanos, Universidad Nacional Autónoma de México \\ e Instituto de Liderazgo en Artistas
}

Indudablemente, el Chilam Balam de Chumayel es uno de los textos más importantes para comprender no sólo la cultura de los mayas sino la cosmovisión mesoamericana en general. Es, además, una creación humana de trascendencia universal.

Para los estudiosos mesoamericanistas y mayistas es una fuente inagotable a la que, por lo general, los hablantes de castellano accedemos a través de ediciones vertidas a nuestro idioma. Ha sido traducido íntegro en tres ocasiones al inglés ${ }^{1}$ y dos veces al francés, aunque estas ediciones no son traducciones directas del maya. $^{2}$

Académicamente hablando, a mi parecer, el mejor prólogo e introducción de las ediciones en castellano del Chumayel son los de Mercedes de la Garza. Además, su edición de la traducción del sabio yucateco Antonio Mediz Bolio mejoró en forma importante este trabajo, pues hizo un cotejo con la de Roys y con $\mathrm{El}$

\footnotetext{
${ }^{1}$ La primera, por el mayista estadounidense Ralph Roys, en 1933; esta edición es base y referencia obligada de traducciones y ediciones posteriores y aún no pierde su vigencia, a pesar de tener limitaciones. Chilam Balam de Chumayel, 1973. Véase al respecto también Barrera Vásquez, 1934: 55-68.

La segunda fue hecha por Munro S. Edmonson, Chilam Balam de Chumayel, 1986, en una edición que no siguió el orden original del texto, sino que lo seccionó para reacomodarlo intentando, a su juicio, darle mayor claridad y orden, de acuerdo a la cronología (lineal) que infirió. Las traducciones de los Chilam Balam de Tizimín y Chumayel que realizó Edmonson han sido duramente criticadas por expertos en maya yucateco. Véase al respecto David Bolles, 1984: 337-341 y William F. Hanks, 1988: 331-364.

La tercera fue realizada por Richard N. Luxton, que publicó su versión en 1995. Este trabajo parte de la premisa de que el lenguaje arcaico del Chumayel aún es comprendido por los especialistas rituales contemporáneos, y se apoyó en hablantes de maya que fuesen j-meno'ob.

${ }^{2}$ En 1955, por el poeta surrealista Benjamin Péret, y en 1976, por el ahora premio Nobel de literatura Jean Marie Le Clézio. Por el oficio de estos dos personajes, los prólogos de las ediciones galas son escritos desde la literatura y están realizados con maestría y belleza, acentuando asimismo el valor literario universal del Chilam Balam. Pueden leerse, en español, el de Le Clézio con una traducción de José de la Colina en el número 34 de la revista Vuelta, de 1979, y el de Péret en $<$ http://www. archivosurrealista. com. ar/Paris41.htm >.
} 
libro de los libros de Chilam Balam, ${ }^{3}$ una labor reconstructiva de Barrera Vásquez y Rendón; como resultado de ello, la editora agregó términos entre corchetes que esclarecen el texto. Asimismo, incluyó diversas notas explicativas a pie de página, que facilitan la comprensión de la obra. Es, pues, hasta nuestros días, la edición más completa del Chumayel en castellano y también, por mucho, la más difundida.

Las ediciones en español que han contado, a lo largo de los años, con mayor difusión en México, como la de Mercedes de la Garza, son las que utilizan la traducción de Mediz Bolio. ${ }^{4}$ Existe también en castellano una edición dirigida por Miguel Rivera Dorado, que, si bien se basó parcialmente en Mediz Bolio, como señala, pasó por la revisión y corrección de Ramón Bastarrachea Manzano y Domingo Dzul Poot, dos grandes conocedores de la lengua maya. ${ }^{5}$ Ambas ediciones coinciden de manera general en la traducción, aunque presentan discordancias, la mayoría de las veces de forma y en una mínima proporción en fragmentos del libro, que, a mi juicio, alteran el sentido de algunas partes del texto original.

Ralph Roys apuntó ciertas dificultades que enfrentó al traducir al inglés este libro escrito en maya con caracteres latinos. Entre ellas destaco las siguientes:

[...] the Book of Chilam Balam of Chumayel is difficult to translate, although the spelling is better on the whole than that of some of the other manuscripts. As Professor Tozzer has noted, many words are separated arbitrarily into syllables, the same word sometimes being divided in several different ways on the same page. $[\ldots]$ The greatest difficulty of all is found in the numerous obsolete words and phrases which occur. It has already been noted that the Chumayel is a compilation made from various earlier works, many of which were probably copied from still older books. ${ }^{6}$

$[\ldots]$ In writing the double vowels, Maya writers are frequently inconsistent. ${ }^{7}$

3 Barrera y Rendón, 1998.

${ }^{4}$ Se trata de una edición costarricense, realizada en 1930, que fue la primera traducción completa del maya al español del Chilam Balam de Chumayel, hecha por Antonio Mediz Bolio.

${ }^{5}$ Ha sido reeditada en varias ocasiones. La más reciente que conozco es una edición venezolana, que no contiene la muy buena introducción de Rivera Dorado, sino una bastante breve y nada docta, firmada con las iniciales C. P. G., que supongo corresponden a la editora Coral Pérez. Los libros de Chilam Balam de Chumayel, 2008.

6 “"...] el libro del Chilam Balam de Chumayel es difícil de traducir, aunque su ortografía es mejor en conjunto que la de algunos otros manuscritos [mayas]. Como el profesor Tozzer ha señalado, muchas de las palabras están separadas de manera arbitraria en sílabas, y la misma palabra se puede encontrar en la misma página dividida de diversas maneras. La mayor dificultad de todas es la gran cantidad de palabras y frases obsoletas que se encuentran en el texto. Ya ha sido anotado anteriormente que el Chumayel es una compilación hecha a partir de varios trabajos más tempranos, muchos de los cuales podrían incluso haberse copiado de libros aun más antiguos" (la traducción es mía), The Book of Chilam Balam of Chumayel, 1973: 8. Dichos textos más antiguos podrían llegar a ser incluso códices prehispánicos.

7 "Los escribanos mayas fueron frecuentemente inconsistentes en la escritura de las vocales dobles” (la traducción es mía). Ibidem: 10. 
$[\ldots]$ The text $[\ldots]$ is not divided into sentences, and many portions are not separated into paragraphs. ${ }^{8}$

Es de subrayar de la cita anterior, para efectos de lo que se propondrá en este texto, el uso de lenguaje arcaico y ritual en fragmentos del Chumayel, ${ }^{9}$ así como el hecho de que los escribas cometieron errores de escritura (lapsus calami). A lo señalado por Roys se suman problemas de edición e impresión que derivaron de manera tangible en las erratas. Todo lo anterior, en suma, distorsiona lo que quisieron plasmar los autores originales de este libro.

Este artículo es un intento por restituir a las traducciones el sentido general de algunos párrafos de la primera página (de hecho la segunda, porque la primera se extravió), ya que en su traducción y edición fueron mutilados o traducidos de manera errónea; también intento recuperar la presencia del saka' (pozol ritual) en el texto, algo que se omitió en todas las traducciones del Chumayel. No trato, pues, de subrayar las diferencias meramente de redacción y estilo, algo en sí mismo enriquecedor, sino que, cotejando el original, pretendo restituir elementos borrados del texto.

Estos sencillos ejercicios son una mínima parte de una gran tarea que nos aguarda: la de perfeccionar las muy buenas traducciones existentes, volviéndolas más fieles al sentido original del texto, para que pueda ser estudiado, comprendido y disfrutado de una manera más cabal. Mi intención no es perfeccionar en su totalidad las traducciones en español, sino llamar la atención sobre esta necesidad.

\section{El rumbo Sur y sus atributos amarillos}

Comenzaré este llamado de atención sobre una discordancia que se da entre dos grupos de ediciones en español del Chilam Balam de Chumayel, las que utilizan la traducción de Mediz Bolio, y las que usan la revisión de Rivera Dorado. Esta discordancia estriba en la presencia o ausencia del maíz amarillo y del frijol espalda

\footnotetext{
8 "El texto $[\ldots]$ no esta dividido en oraciones, y muchas partes no están separadas en párrafos" (la traducción es mía). Ibidem, p. 11.

${ }^{9}$ En este punto es preciso recordar lo que atinadamente señala Mercedes Montes de Oca: "El léxico arcaico es otra de las marcas especiales del lenguaje ritual [...] Es un tipo de vocabulario que es transmitido junto con el género aunque sea difícil de comprender aun para aquellos que dominan la lengua" (2005: 561). Para ejemplificar el uso de un lenguaje o palabras arcaicas entre los mayas peninsulares recurro a mi propia experiencia de campo y archivo. Consigné lo siguiente en un escrito sobre la especialista ritual Lupe Cohuo de Maxcanú: "Verónica se dice sorprendida por la invocación que ha cantado el hermano, y comenta que 'debe ser muy antiguo' y que ella nunca la había escuchado pues el hermano Andrés nunca había revelado tales invocaciones. Además subraya que, si bien no está en otra lengua, sí es un habla especial. 'Es la maya pero no se entiende todo, casi no se entiende', dijo reiterando que debe ser 'muy antiguo'. Lo anterior concuerda con los documentos coloniales que he trabajado y con diversas etnografías que refieren que los $j$-men utilizan cierto lenguaje especializado" (Vassallo, 2012: 96).
} 
amarilla, asociados al rumbo Sur del cosmos (cada grupo omite a uno de los dos), en la primera página. ${ }^{10}$ De inicio debo hacer patente que, en mi opinión, ambos grupos están errados, pues suprimen alguno de estos dos elementos, como intentaré demostrar. Lo anterior se antoja algo baladí, pero indubitablemente estas omisiones alteran lo que yo supongo fue el sentido original de ese fragmento del texto que otorga a cada cuadrante del cosmos atributos desplegados a partir de elementos que se encuentran en el axis mundi.

Con anterioridad he planteado ${ }^{11}$ que los autores del Chumayel plasmaron al principio del texto, de manera consciente, ciertos elementos relevantes constitutivos de los cuadrantes del cosmos de la era maya presente. ${ }^{12} \mathrm{~A}$ mi juicio su intención era describir de inicio el orden del mundo. ${ }^{13}$ Como otros pueblos mesoamericanos los mayas pensaban que habían existido otras eras con sus respectivas humanidades pero que fueron destruidas dando lugar a la presente creación. En un pasaje posterior del Chilam Balam de Chumaye ${ }^{14}$ se asentó que la era inmediatamente precedente fue destruida por los Bacabo'ob, que provocaron un diluvio. Estos cuatro Bacabes fueron los que posteriormente nivelaron el mundo actual. Una vez hecho lo anterior plantaron los árboles (ceibas) que fungen como pilares en las cinco direcciones del cosmos (uno por cada rumbo). Como bien han señalado Roys, ${ }^{15}$ De la Garza ${ }^{16}$ y Rivera Dorado, ${ }^{17}$ el pasaje contenido en el Chumayel, aunque incluye a la Ceiba verde del rumbo centro, está incompleto, pues no menciona a la Ceiba roja del Oriente. Pero el pasaje que narra este evento sí está completo en los Chilames de Tizimín y de Maní. Al realizar una reconstrucción del pasaje, Alfredo Barrera Vázquez y Silvia Rendón utilizaron estos tres libros, resultando lo siguiente:

Al terminar el arrasamiento se alzará Chac Imix Che, la ceiba roja, columna del cielo, señal del amanecer del mundo, árbol del Bacab, Vertedor, en donde se posará Kan Xib Yuyum, Oropéndola-amarilla-macho. Se alzará también Sac Imix Che, Ceibablanca, al Norte; allí se posará Zac Chic, Blanco remedador, Zenzontle; soporte del cielo y señal del aniquilamiento será la ceiba blanca. Se alzará también Ek Imix Chec [sic por che], Ceiba-negra, al Poniente del país llano; señal del aniquilamiento será la ceiba negra; allí se posará Ek Tan Picdzoy, Pájaro-de-pecho-negro. Se alzará

${ }^{10}$ Para saber qué versión era la correcta, si la que omitía o la que consignaba al maíz y/o al frijol, recurrí a las versiones del original accesibles para mí, es decir, la fotográfica, publicada por G. B. Gordon en 1913, y la digitalizada por la Universidad de Princeton, que actualmente tiene en su poder el manuscrito, la cual se puede consultar en su biblioteca digital: <http://arks.princeton. edu /ark:/88435 /0z708w51x>.

${ }^{11}$ Vassallo, 2015: 318.

12 Por ello y otras razones disiento del orden propuesto por Edmonson (1986), que alteró el del texto original.

${ }^{13}$ Utilizo la palabra mundo en su acepción de "conjunto de todas las cosas creadas".

14 Roys (1973) lo intituló "The creation of the World"; Mediz Bolio (1930) y De la Garza (2006), "Libro de los antiguos dioses", y Rivera Dorado (2003), "Los viejos y los nuevos dioses".

${ }^{15}$ Véase al respecto Chilam Balam de Chumayel, 1973: 2.

${ }^{16}$ Chilam Balam de Chumayel, 2006: 89, n. 7.

${ }^{17}$ Chilam Balam de Chumayel, 2003: 92, n. 19. 
también Kan Imix Che, Ceiba amarilla, al Sur del país llano, como señal del aniquilamiento; allí se posará Kan Tan Picdzoy, Pájaro-de-pecho-amarillo, Kan Xib Yuyum, Oropéndola-amarilla-macho, Ah Kan Oyal Mut, Ave-vencida-amarilla. Se alzará también Yaax Imixche, Ceiba-verde, en el centro de la provincia como señal y memoria del aniquilamiento. Ella es la que sostiene el plato y el vaso; la Estera y el Trono de los katunes por ella viven. ${ }^{18}$

La redacción de los párrafos anteriores, si bien no es idéntica, es similar y repetitiva. Lo mismo sucede en los Chilames originales que contienen el pasaje, grosso modo cambia solamente la especificidad del color de cada ceiba y el pájaro que le corresponde. Podemos ver el mismo estilo narrativo, para describir elementos desdoblados en los rumbos del cosmos, en la página tres (cuatro) del Chumayel:

La gran Abeja $\left[{ }^{19}\right]$ Roja es la que está en el Oriente. La rosa roja es su jícara. La flor encarnada es su flor.

La gran Abeja Blanca es la que está en el Norte. La rosa blanca es su jícara. La flor blanca es su flor.

La gran Abeja Negra es la que está en el Poniente. El lirio negro es su jícara. La flor negra es su flor.

La gran Abeja Amarilla es la que está en el Sur. El lirio amarillo es su jícara. La flor amarilla es su flor. ${ }^{20}$

Se puede apreciar que en la redacción existe una estructura casi completamente repetitiva y que sólo cambia en cada párrafo el color de cada cuadrante, su rumbo cardinal y el tipo de flor que le corresponde. Por lo demás, los párrafos son idénticos. Este tipo de cuádruplos se encuentran no solamente en este y otros textos mayas, sino también, y sobre todo, en el lenguaje ritual de los pueblos mayanses, siendo un complemento de elementos pareados como "el cerro-el llano", "subida-bajada", "grande-chico"... ${ }^{21} \mathrm{Si}$ estos últimos reflejan parejas de opuestos complementarios, considero que los cuádruplos siempre implican características cuadruplicadas del axis mundi, desplegadas en los cuadrantes del cosmos. Se trata de un paralelismo estructurado en cuatro, que es marca de lenguaje ritual; si bien estos cuádruplos no son cuartetas, en el sentido de las métricas occidentales, propongo llamarlos así, ya que tienen una rítmica propia de los rezos: ${ }^{22}$ pueden

18 Barrera y Rendón, 1998: 91-92.

${ }^{19}$ La traducción de Mediz Bolio, en vez de “La gran Abeja”, asienta “El calabazo" (1930: 19).

${ }^{20}$ Chilam Balam de Chumayel, 2006: 42.

${ }^{21}$ Aunque pudiéramos considerar estos pares como difrasismos, no son como los prototípicos nahuas, ya que no siempre se genera un significado diferente. En las oraciones mayas pueden ser opuestos complementarios que aludan a la totalidad, aunque en ocasiones sí se genera otro significado. Por ejemplo: sin subida, sin bajada [con caminos planos, con lindos caminos planos], quiere decir "sin problemas".

22 Montes de Oca señaló la relevancia de encontrar ciertos patrones y números en las narrativas indígenas y que "incluso se ha planteado que además de alteraciones en los diferentes niveles de la lengua, las narrativas tienen un principio organizativo en función de un número que es significativo a 
estar compuestas por una o más oraciones para cada una de sus cuatro partes y la estructura general es la misma y repetitiva. En algunas ocasiones, en este tipo de composiciones, el cuadrante está implícito al mencionar a los colores rojo, negro, blanco y amarillo; es decir, si encontramos oraciones, o grupos de éstas, en conjuntos de cuatro donde aparezcan tales colores en forma subsecuente, tácitamente se está hablando de elementos correspondientes a cuadrantes o rumbos del cosmos. ${ }^{23}$

Aunque aún no había desarrollado esta propuesta de las cuartetas, en un trabajo previo $^{24}$ había señalado que llama la atención que en las traducciones del Chumayel al español no estuvieran presentes en la primera página ciertos elementos que debieran aparecer, siguiendo la estructura lógica (en cuartetas) del propio Chilam Balam y de otros textos mayas. ${ }^{25}$ Señalaba además que los elementos repetitivos que explican los rumbos y sus atributos son acordes con ideas centrales de la cosmovisión mesoamericana. Los mayas que redactaron el Chumayel, como otros mesoamericanos, tenían la creencia de que en el axis mundi se encontraban ciertos elementos como el árbol primordial y un pájaro que se encontraba posado en su copa; este árbol estaba sobre una montaña. En dicho escrito anteriormente publicado propuse que la piedra (tun) que aparece en la primera página del Chumayel es una metáfora de la montaña primordial, lo cual no me resultaba extraño ya que es acorde con el estilo de los mitos de origen del maíz, donde dicha pieza de la cosmovisión mesoamericana (Tonacatépetl, Paxil u otro de sus nombres locales) puede ser denominada, dentro del relato, cerro, peña o piedra. ${ }^{26}$ Anotaba que en el caso del Chumayel se dice que la piedra es el pedernal y se desdobla en cada rumbo adquiriendo el color de éste, y que, por ser la montaña primordial (lo primero que surgió de las aguas después de diluvio), es por ello que encabeza la lista de elementos constituyentes de cada uno de los rumbos. No solamente la montaña se desdobla en los cuadrantes, también lo hacen otros elementos culturalmente

nivel ritual, ceremonial, social, etcétera. De esta manera, en algunas narrativas, el número de párrafos, escenas, versos, personajes, acciones, está relacionado con este número relevante, por ejemplo, en la narrativa en lengua chinook, el cinco sería este número eje. En algunas regiones de Mesoamérica se puede pensar en el número dos o tal vez su correlato en cuatro. Se trataría entonces de una correspondencia entre los patrones que se dan a nivel narrativo y los que se dan en el ámbito cultural" (2005: 554-555).

${ }^{23}$ En el Ritual de los Bacabes (2007) se encuentran 47 de estas cuartetas y solamente en una se hace referencia explícita a los cuadrantes del cosmos; en el resto sólo se mencionan los colores-atributo de estos, y el orden de los colores será el mismo que en el Chumayel: rojo, blanco, negro y amarillo, es decir, Oriente, Norte, Poniente, Sur; corriendo en sentido inverso a las manecillas del reloj. Solamente en una de las cuartetas (que habla de sangre, p. 144) el orden será diferente: negro, rojo, amarillo, blanco, probablemente se trate de un lapsus calami del escribano, pues en las 46 restantes el orden es el mismo.

${ }^{24}$ Vassallo, 2015: 319.

${ }^{25}$ Llama asimismo la atención que De la Garza y Rivera Dorado, habiendo subrayado el faltante de la Ceiba Roja en el pasaje de la creación de la era actual, no señalen nada sobre la falta de un elemento (maíz o frijol) asociado al cuadrante Sur del cosmos.

${ }^{26}$ Para reforzar mi propuesta podemos ver cómo en el mito del origen del maíz consignado en el Chumayel (2006: 99), que es un mito cognado de otras versiones de los pueblos mayas y mesoamericanos, el maíz está encerrado en una roca, que es una forma de llamar a la montaña en este tipo de relatos. 
relevantes: ceiba, guajolote, frijol y maíz. ${ }^{27}$ Así, en cada párrafo que describe a un rumbo determinado, aparece un atributo que es equivalente y similar. Esto por el hecho de provenir de un elemento que se encuentra en el centro, que en su desdoblamiento por cada cuadrante adquiere una especificidad reflejada en un color diferente, que es el del rumbo que le corresponde. Al fisionarse ya no será la ceiba o el maíz [verde] del axis mundi, sino su desdoblamiento, ceiba blanca o maíz blanco, ceiba roja o maíz rojo, ceiba negra o maíz negro, ceiba amarilla o maíz amarillo. Entonces el texto tendría que mencionar, siguiendo la estructura de las cuartetas de las oraciones mayas, el tipo de maíz (que es un elemento central y primordial) que se desdobló para el rumbo Sur, y no lo hace en las ediciones que se basan en Mediz Bolio (1930), mientras que Rivera Dorado (2003) omite al frijol del mismo rumbo. Por otro lado, existe una constante: en ninguna edición en español del Chumayel aparece el frijol rojo del Oriente que debería, a mi juicio, estar presente.

Para facilitar la comparación entre la versión del Chilam Balam de Chumayel más difundida y la que se podría considerar atípica, podemos ver la transcripción de los párrafos de cada una de ellas, correspondientes a los cuatro rumbos cardinales y sus atributos. La de la derecha es la edición de Mediz Bolio (op. cit.), representativa de las que omiten al maíz amarillo, y la de la izquierda es la de Miguel Rivera Dorado (op. cit.), donde sí aparece, pero que no menciona al frijol de espalda amarilla:

El pedernal rojo es la sagrada piedra de Ah Chac Mucen Cab. La Madre Ceiba Roja, su Centro Escondido, está en el Oriente. El chacalpucté es el árbol de ellos. Suyos son el zapote rojo y los bejucos rojos. Los pavos rojos de cresta amarilla son sus pavos. El maíz rojo y tostado es su maíz.

El pedernal blanco es la piedra sagrada del norte. La Madre Ceiba Blanca es el Centro Invisible de Sac Mucen Cab. Los pavos blancos son sus pavos. Los frijoles lima blancos son sus frijoles. El maíz blanco es su maíz.
El pedernal rojo es la sagrada piedra de Ah Chac Mucen Cab. La Madre Ceiba Roja, su Centro Escondido, está en el Oriente. El Chacalpucté es el árbol de ellos. Suyos son el zapote rojo y los bejucos rojos. Los pavos rojos de cresta amarilla son sus pavos. El maíz rojo y tostado es su maíz.

El pedernal blanco es la piedra sagrada del norte. La Madre Ceiba Blanca es el Centro Invisible de Sac Mucen Cab. Los pavos blancos son sus pavos. Las habas blancas son sus habas. El maíz blanco es su maíz.

\footnotetext{
${ }^{27}$ Cabe anotar algo que también mencioné en dicho trabajo anterior y es que en otras versiones mesoamericanas el maíz es intercambiable o equivalente al árbol del centro, pero en el Chumayel ambos elementos, siendo simbólicamente el mismo, se encuentran fisionados. Agregaría que esto subraya el papel preponderante del maíz para los pueblos mayas.
} 
El pedernal negro es la piedra del poniente. La Madre Ceiba Negra es su centro escondido. El maíz pinto es su maíz. El camote de pezón negro es su camote. Las palomas negras silvestres son sus pavos. El akab chan (variedad de maíz) es su maíz. El frijol negro es su frijol. El frijol lima negro es su frijol.

El pedernal amarillo es la piedra del sur. La Madre Ceiba Amarilla es su centro escondido. El pucté amarillo es su árbol. El pucté amarillo es su camote. Las palomas silvestres amarillas son sus pavos. El maíz amarillo es su mazorca. ${ }^{*}$
El pedernal negro es la piedra del poniente. La Madre Ceiba Negra es su centro escondido. El maíz negro y acaracolado es su maíz. El camote de pezón negro es su camote. Los pavos negros son sus pavos. La negra noche es su casa. El frijol negro es su frijol. El haba negra es su haba.

El pedernal amarillo es la piedra del sur. La Madre Ceiba Amarilla es su Centro Escondido. El pucté amarillo es su árbol. Amarillo es su camote. Amarillos son sus pavos. El frijol de espalda amarilla es su frijol.**

Como podemos ver, a pesar de estas discordancias, ambas versiones coinciden de manera general, y la mayoría de sus diferencias son de matiz o estilo. Es evidente que la redacción repetitiva de los parágrafos sirve para subrayar el hecho de que cada atributo es equivalente y similar, pues proviene de un elemento central. En consecuencia, el texto de la derecha tendría que mencionar, apegándose a las cuartetas mayas, el tipo de maíz que se desdobló para el rumbo Sur, y no lo hace; mientras que el de la izquierda debería presentar en ese mismo rumbo un frijol que no aparece. Además ambos deberían tener un frijol al Oriente. En el original sí están completas las cuartetas, por lo que estos faltantes son un problema de edición y/o traducción.

El desdoblamiento de los elementos del axis mundi en cuadrantes, donde adquieren el color característico de cada rumbo, permanece hasta nuestros días en el pensamiento de los mayas peninsulares; un ejemplo nítido de ello es que, en una ocasión, Alfonso Dzib, un j-men de Xocén, Yucatán, nos dijo a Ana Ortiz (mi esposa) y a mí que "Chaak es uno, pero es muchos con sus esposas y sus rumbos" (es decir que se desdobla en cada rumbo y también en masculino y femenino), y a continuación, señalando dónde estaban sus casas, acotó de qué color eran ellos y sus esposas, así como de qué color era el agua que repartía cada uno de ellos: "el Chaak blanco, que vive por Cancún, trae lluvia blanca, es mala para el maíz, lo mata, pero es buena para que abunde el macal, las jícamas, los camotes, la yuca" (es decir frutos subterráneos que se crían más cerca del inframundo). Y así nos fue describiendo uno por uno, cada atributo se repetía en cada rumbo, pero con la especificidad inherente a cada uno. Siguiendo esta lógica, el texto de la columna de la derecha, aun sin conocer la versión de la izquierda, ya se ve trunco,

* Chilam Balam de Chumayel, 2003: 58 (el subrayado es mío).

**** Chilam Balam de Chumayel, 1930: 17-18 (el subrayado es mío). 
y viceversa. Esta concepción hunde sus raíces en la cosmovisión mesoamericana anterior a la invasión europea. Ana García Barrios apunta:

En lo relativo al aspecto cuatripartita que marcan los árboles, colores y pájaros, hay que señalar que Chaahk es también un dios cuatripartita[ $\left.{ }^{28}\right]$ y está en estrecha relación con los árboles. Ciertos apelativos clásicos del dios dejan testimonio de este aspecto, como se aprecia en el nominal procedente de Comalcalco: Chan Xob' Te' Chaahk "Chaahk de cuatro árboles Xob" " y otros que le vinculan con otros árboles, como Ahku'l lib', Te' Chaahk "Chaahk tortuga de árbol Ib'”, en este caso tortuga es sinónimo de Tierra [...]. Esta asociación cuatripartita en relación con los árboles y con la tortuga como símbolo del interior de la tierra, se aprecia también en los manuscritos posclásicos. En las páginas 29a (62) y 30a (63) del Códice de Dresde [...], Chaahk está sobre cuatro árboles y una quinta escena le muestra en el interior de una cueva, que identifica el centro. La disposición de estas imágenes es similar a la reproducida en los murales de San Bartolo, donde a las escenas de los árboles le sigue una cueva en forma de tortuga en cuyo interior se encuentra Chaahk. Los textos que acompañan a las cuatro imágenes del Códice de Dresde están en relación con los colores que indican los sectores cardinales, chak, "rojo", sak, "blanco"; ek', "negro", k'an, "amarillo" y el quinto es yax, "verde" (la lectura de este último está perdida), indicado el centro por la cueva. Las páginas siguientes del Códice de Dresde, 30c (63) y 31c (64) [...] representan igualmente a Chaahk sobre cuatro árboles y ligados a los cuatro colores de las direcciones, marcados en este caso por los nombres de los puntos cardinales. ${ }^{29}$

La desaparición del maíz amarillo en el rumbo Sur, en las ediciones de mayor difusión, es una omisión recurrente. Sin temor a equivocarme puedo afirmar, después de revisar muchas ediciones y reediciones, que la raíz de esta omisión se encuentra en la edición costarricense del trabajo de Mediz Bolio. Un dictaminador anónimo de este artículo me hizo notar que, en la edición de 1930, el erudito yucateco anotó en las erratas importantes de esta edición: "Parte I.- Página 18,

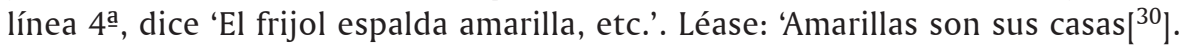

\footnotetext{
${ }^{28}$ A este señalamiento de Ana García agregaría yo que Ix Chel también es una diosa cuatripartita, como está asentado en el Ritual de los Bacabes: "Habrá de llegar hasta la morada de Chacal Ix Chel, 'Ix Chel-la-roja'; de Sacal Ix Chel, 'Ix Chel-la-blanca'; de Ekel Ix Chel, 'Ix Chel-la-negra'; de Kanal Ix Chel, 'Ix Chella-amarilla' (2007: 79). Estoy totalmente en desacuerdo con Thompson cuando afirma: "El que compuso el Ritual de los Bacabes atribuyó colores del mundo, a veces rumbos también a tantas personas y cosas que uno no sabe cómo tomar la referencia a las cuatro Ix Chel con sus colores. Yo me inclino a pensar que sólo había una Ix Chel, que la mención de las cuatro era un mero abracadabra, y que muchas asociaciones de objetos con los colores del mundo se recitaban también para impresionar al paciente pero en realidad habían sido una invención del autor" (2008: 302). Creo que este mayista no dimensionó hasta qué punto se podían fisionar las deidades mayas y que sus atributos podían ser varios y variados, además de que tampoco tomó en cuenta que los elementos del Centro se despliegan en cuadrantes.

${ }^{29}$ García, 2009: 107.

${ }^{30}$ En lugar de traducir nal (que aparece dos veces en la página) por "maíz”, Mediz Bolio tradujo "casas". Cabe apuntar que el texto original dice nal u nalob, lo que a mi juicio habla del maíz. Esto abre la posibilidad de que Mediz Bolio haya interpretado como nalil una forma compuesta de na ("casa"); el Motul en su foja 322v define: "nalil, la casa la gente de casa: vsase postpuesta y con esta particula ti [...]". Cabe apuntar que nail se utiliza más para referirse a los habitantes de la casa que a la construcción, lo que hace aún más incoherente la traducción y la aleja del concepto de elementos desdoblados del centro.
} 
El frijol espalda amarilla es su frijol'."' ${ }^{31}$ Es decir, Mediz Bolio fue consciente de que se borró una parte del texto, pero su traducción no incluye al maíz. ${ }^{32}$ El borrar su presencia, innegable en el original maya, fue pasando de edición en edición, pues a estos párrafos no se les cambió ni una coma, ya que ni la errata se corrigió ni se incluyó al maíz amarillo. Como he señalado en una publicación previa, ${ }^{33}$ este faltante se ha repetido de manera subsecuente en las ediciones y reediciones de la traducción de Mediz Bolio, es decir, las de la UNAM realizadas en 1941,34 1952 y 1973; la perteneciente a la antología de textos mayas de la Biblioteca Ayacucho de Venezuela, publicada en 1980, ${ }^{35}$ y la edición más difundida en México, es decir, la perteneciente a la colección Cien de México, publicada en 1985 por la SEP (CONAFE-DGP), ${ }^{36}$ y reeditada en 1993 por el CONACULTA, ${ }^{37}$ que heredó la colección y la ha seguido publicando desde entonces.

Supongo que algunos estudiosos se habrán dado cuenta de que falta el maíz amarillo del rumbo Sur, como notó perspicazmente Laura Sotelo, quien infirió, supongo que a partir de la edición más difundida, que el faltante era de la obra y no un problema editorial. ${ }^{38}$

Es preciso dejar en claro que tanto en el original como en la transcripción que Ralph Roys hizo del manuscrito, sí aparece el maíz amarillo, lo que da al texto un sentido más cabal, ya que a cada rumbo le corresponde un tipo de maíz con su respectivo color asociado. Veamos la paleografía de Roys del párrafo del rumbo Sur y su traducción al inglés:

Kan tok tun u tunil u nohol imix <ya >xche. Kan imix yaxche u oulbalob. $\left[{ }^{39}\right]$ Kanal pucte u cheob. Ix kan pucte yizilob. Ix kan pucte ucum yulumob. Ix kakan pal nal u nalob. Ix kan pach u buu $<\mathrm{l}>$ ob cah.../cu $<$ ch $>$ ob. ${ }^{40}$

${ }^{31}$ Chilam Balam de Chumayel, 1930: p. sin número.

32 Muchos años después Mediz Bolio sí asoció al maíz con los cuadrantes del cosmos, pues escribió en un ensayo: "Desde los remotos misterios cósmicos, el maíz figura, simbólicamente, como signo de los primeros hombres que aparecen en el Mayab para poblarlo, desde los cuatro puntos cardinales. 'El maíz rojo es atributo de los hombres de Oriente, el maíz blanco de los del Norte, el maíz negro de los del Poniente, el maíz amarillo de los del Sur'. Con el color que esotéricamente corresponde a cada uno de los cuatro rumbos de la tierra se marca el divino grano que es la expresión de la vida de las cuatro grandes familias humanas que pueblan el mundo". Mediz, 1970: 62-67.

33 Vassallo, 2015: 320.

${ }^{34}$ Véase al respecto la p. 4 de la edición del Chilam Balam de Chumayel de 1941.

35 Esta antología de textos mayas escritos en caracteres latinos, que cuenta con un excelente estudio introductorio de Mercedes de la Garza, incluye una versión del Chilam Balam de Chumayel, con la introducción de Mediz Bolio; en la página 220 está el párrafo en cuestión (De la Garza, 1980).

${ }^{36}$ Véase Chilam Balam de Chumayel, 1985, 41.

${ }^{37}$ Chilam Balam de Chumayel, 2006, 41.

${ }^{38}$ Véase Sotelo, 2002: 126.

39 A principio del período colonial los frailes franciscanos, que comenzaron a utilizar caracteres latinos para escribir el maya peninsular, desarrollaron convenciones para representar sonidos inexistentes en castellano; así, la "c" invertida (o) fue utilizada para representar el sonido "dz", por lo que oulbalob debe leerse dzulbalo'ob.

${ }^{40}$ Chilam Balam de Chumayel, 1973: 15. 
The yellow flint stone is the stone of the south. The Ceiba tree of abundance, the yellow Ceiba tree of abundance, is their arbor. The yellow bullet-tree is their tree. $<$ Colored like $>$ the yellow bullet- tree are their camotes. $<$ Colored like $>$ the yellow bullet-tree are the wild pigeons which are their turkeys. Yellow green corn is their corn. Yellow-backed are their beans... ${ }^{41}$

Si prestamos atención a la traducción de Roys podemos ver que asienta yellow green corn. En este caso, green ("verde") se refiere a su estado de maduración y no a su color, que es yellow (“amarillo”); con esto Roys nos está diciendo que el texto habla de elote y no de maíz desgranado o maduro y seco. ${ }^{42}$ En el original en maya, en los párrafos del texto que hablan del maíz asociado a los rumbos, aparecen las palabras ixim ("el grano de maíz”) y nal ("planta”, "elote”, y "mazorca”), es decir, se hace una diferencia entre el maíz desgranado y la planta con su fruto, ya sea tierno o maduro. Esto es algo que no se reflejó en ninguna de las traducciones al español, que uniforman las dos etapas utilizando solamente el vocablo maíz. También es preciso apuntar que estos dos términos figuran en el texto original la mayoría de las veces con posesivos y en plural: yiximo'ob ("sus granos de maíz o sus maíces desgranados”) y unalo’ob (“sus maíces”).

En el original se anotó, en lo correspondiente al Este y al Norte, la palabra maya para grano de maíz, que aparece poseída y en plural, de acuerdo a mi paleografía textualmente dice yx chac opool yiximo'ob (para el Oriente) y Saca ixim yiximo'ob (para el Septentrión); en otro rumbo (el Poniente) están en el mismo párrafo las palabras para maíz y su grano $e k$ hub ${ }^{43}$ yiximo'ob y Ek akab chan u $\underline{\text { nalob; }}{ }^{44}$ en el rumbo restante, es decir, el Sur, no figura la palabra para grano o maíz desgranado, pero sí el vocablo para maíz, ix kakan nal u nalob.

La presencia y ausencia del maíz y del grano en estos párrafos ubicados casi al inicio del Chumayel $^{45}$ abren la posibilidad de que en las sucesivas transcripciones antiguas del texto maya se hayan perdido los maíces desgranados correspondientes al Oriente y al Norte, así como el maíz en el Sur, quedando completo solamente el Poniente, es decir, con su maíz y su grano.

Por otro lado, la desaparición del frijol espalda amarilla de la edición de Rivera Dorado tiene su raíz en sí misma, repitiéndose en sus reediciones. Estoy seguro de que los autores de esta edición y traducción omitieron la parte del texto ori-

41 Ibidem: 64.

42 Lo mismo hace Luxton (1995: 3), que traduce yellow young corn (“elote amarillo"), mientras Edmonson (1986: 105) optó por yellow corn ears ("mazorcas de maíz amarillo").

43 Llamado actualmente éek' jub y también éek' chob, es una variedad de maíz harinoso, raza "tuxpeño" rojo oscuro, morado o azul casi negro. Es un tipo de maíz ritualmente importante ya que se le menciona en el Ritual de los Bacabes (2007: 139).

44 La traducción de Mediz Bolio también omite una de las dos menciones del maíz. La edición de Rivera Dorado, por su parte, más fiel al texto original, sí pone dos tipos de maíz en este párrafo, pero no hace diferencia entre si está desgranado o no.

${ }^{45}$ Conviene recordar que la primera página del manuscrito está extraviada. 
ginal que dice claramente $Y x$ kan pach u buu[l]ob 46 ("espalda amarilla es su frijol”), lo que dejó trunca su versión.

\section{El Oriente ¿carece de leguminosa roja?}

Es preciso anotar que las leguminosas asociadas en el Chumayel con cada uno de los rumbos se pueden agrupar en dos: frijoles e ibes. El término frijol subsume en español a varias especies de leguminosas comestibles y puede abarcar semillas (todas del género phaseolus) que en las taxonomías indígenas y botánica son claramente distinguibles:

El género Phaseolus (subtribu Phaseolinae, tribu Phaseoleae, familia Leguminosae [fabaceae]) tiene una compleja historia taxonómica y de nomenclatura [...]. Las recientes investigaciones filogenéticas apoyan fuertemente un [género] Phaseolus monofilético. [...] [pero] todavía persiste un debate sobre el número de especies que lo conforman. A pesar de lo anterior probablemente existen unas 50 especies en este género, de las cuales cinco son domesticadas: el frijol común (P. vulgaris $L$.), el frijol lima (P. lunatus $L$.), el ayocote (P. coccineus $L$.), el frijol tepari (P. acutifolius $A$. Gray) y el bótil (P. polyanthus Greenm). Estas cinco especies domesticadas pertenecen a dos linajes distintos. El grupo de $P$. vulgaris incluye a $P$. coccineus, $P$. polyanthus y $P$. acutifolius. La quinta especie cultivada, $P$. lunatus, es parte de un clado separado y bien definido, el cual incluye la diversificación sudamericana e insular de Phasoleus [...]. ${ }^{47}$

Aunque morfológicamente similares, el náhuatl distingue entre dos especies distintas de leguminosas: ayecotli ${ }^{48}$ (Phaseolus coccineus), conocido en español del centro de México como ayocote, y etl ${ }^{49}$ (Phaseolus vulgaris), al que de manera genérica llamamos frijol y que en maya peninsular recibe el nombre de bu'ul. A su vez, en la taxonomía de esta última lengua, se hace una clara distinción entre dos especies diferentes de leguminosas, que se consumen ampliamente en la región, el ya nombrado bu'ul (Phaseolus vulgaris) y el iib (Phaseolus lunatus), que en el español de la península se conoce como ib o ibes. ${ }^{50}$ El Calepino de Motul define así a estas dos leguminosas: "buul: frisoles pequeños en genelar [sic por general], assi la mata o mucha fruta"; 51 "ib. Frisoles grandes como hauillas y la mata que

46 La paleografía es mía.

47 Baudoin et al., 2004: 3 (la traducción es mía).

48 "Ayecotli. Frisoles gordos”, fray Alonso de Molina, 2001: 17, foja 3v. "Ayacotli o ayecotli s. Frijoles muy grandes, como habas”, Siméon, 2002, s. v.

49 "Etl. Frisol o haua”, fray Alonso de Molina, 2001: foja 29r. "etl s. Frijol o haba [...]”, Siméon, 2002: 150 .

50 “ $[I] I b$, (Phaseolus lunatus, L.). Variedad ancha y gruesa de frijol blanco, propia de Yucatán. Úsase mayormente en plural españolizado, ibes”, Suárez, 2013.

${ }^{51}$ Ciudad Real, 1984: f. 57 (la paleografía es mía). El mismo Acuña reconstruye en una edición posterior: "frisoles pequeños en general, así la mata <c $>$ om $<$ o s $>$ u frut $<$ o $>$ ", Ciudad Real, 2001: 90. 
los lleva. Es gené|ri]co". ${ }^{52}$ Asimismo, en las taxonomías indígenas existen definiciones muy claras para las subespecies de estos dos tipos de leguminosas.

En la parte del manuscrito original del Chumayel que se refiere a los rumbos y sus atributos, aparecen estos dos tipos de leguminosas (bu'ul e iib), traducidos como "frijol" y "haba" (Mediz Bolio) o como "frijol" y "frijol lima" (Rivera Dorado). Estoy totalmente de acuerdo en traducir bu'ul como "frijol", pero considero que traducir iib como "haba" (Vicia faba) es impreciso, ya que, si bien ambas leguminosas son morfológicamente similares, su tamaño no lo es: las habas son más grandes que un frijol promedio, y los ibes son más pequeños que éstos. ${ }^{53}$ El uso del término haba para designar al Phaseolus lunatus se debe a que las variedades sudamericanas son del tamaño de las habas, mientras que las variedades mesoamericanas, que se domesticaron en forma independiente, son mucho más pequeñas. ${ }^{54}$ Es por ello que la traducción de iib como "frijol lima" es, a mi juicio, más acertada (Roys, Edmonson y Luxton también la usaron), ya que así se conoce al Phaseolus lunatus en varias partes del continente americano, ${ }^{55}$ y los agrónomos suelen otorgarle ese nombre común para uniformar sus diversos nombres locales. Aunque una traducción más fiel debería usar el término del español de la península: ibes. ${ }^{56}$

Se ha repetido ad infinitum que en la dieta básica mesoamericana se encuentran las calabazas, el chile, el maíz y los frijoles. Siendo preeminentes estos dos últimos, su presencia entre los elementos constituyentes de los cuadrantes del cosmos no es sorprendente. La relevancia de las leguminosas bu'ul e iib como elementos del centro que se desplegarán de manera cuatripartita por los rumbos puede apreciarse en ritos llevados a cabo por un sacerdote de la Chontalpa del período Clásico maya. Marc Zender, Ricardo Armijo y Miriam Gallegos (2001) realizaron un estudio epigráfico de varios pendientes y puntas de raya encontrados en una urna funeraria del templo II de Comalcalco, lo que arrojó un corpus documental de 40 textos (la mayoría relacionados con eventos de la vida de Aj Pakal Tahn acaecidos entre 767 y 777 n.e.). De ellos, 16 nos hablan de 12 rituales anuales consecutivos de "pedidas de aguas", donde están presentes este personaje y el dios Chaak, que aparece en diferentes facetas o con diversos atributos. En dos

\footnotetext{
52 Ciudad Real: 1984, f. 221 (la paleografía es mía). René Acuña, en una edición posterior, reconstruyó así la parte faltante del texto original: "ib. Frisoles grandes como hauillas y la mata que los lleva es gene<ralmente > co<lorado>" (Ciudad Real, 2001: 301), lo que a mi juicio es inexacto ya que los ibes más comunes son los blancos. Considero que el redactor del Calepino tal vez escribió: "es genérico", lo cual resultaría más lógico, ya que existen varios tipos de ibes.

${ }^{53}$ Recordemos que en el Calepino de Motul se dice que son "habillas", es decir, se describe como una semilla más pequeña que las habas, el referente ibérico empleado para describir esta leguminosa.

54 De hecho, la botánica tiene claro que existen dos variedades de esta leguminosa que se distinguen por su tamaño y origen Phaseolus lunatus var. Limenanus, que es grande y andina, y Phaseolus lunatus var. Lunonnus, la variedad mesoamericana, más pequeña.

55 El apelativo "lima” proviene del hecho de que Perú ha sido un gran productor y exportador de estas leguminosas.

$56 \mathrm{Si}$ se restituyera, en ediciones venideras, el término original, que no es empleado más allá de la península de Yucatán, se podría poner una nota explicando el vocablo.
} 
de estas ceremonias (que se verificaron de manera consecutiva) aparecen los ibes y los frijoles como facetas o atributos de la deidad pluvial:

9.16.16.1.17 1 k'aban 10 sip, Marzo de 767d.C. Aj Pakal tahn fue llevado con su dios Yaax B'ul Chaak, aspecto del dios de la lluvia.

9.16.17.2.2 2 ik' 10 sip Marzo de 768 d.C. Aj Pakal tahn fue llevado con su dios Ahku'l l'b Te' Chaak, algún aspecto del dios de la lluvia. ${ }^{57}$

La posible traducción de Yaax b'ul Chaak sería "Chaak frijol verde", y por su color pertenecería al centro. Recordemos que en todas las lenguas cholanas y yucatecanas la voz para frijol es b'uul o alguna ligera variante de ésta. ${ }^{58}$ Para Ahku'l I'b Te' Chaak retomemos a la ya citada Ana García, quien tradujo esa frase como "Chaahk tortuga de árbol Ib". 59

Las leguminosas que aparecen asociadas a los rumbos en diversas traducciones del Chumayel son:

\begin{tabular}{|c|c|c|c|c|}
\hline Traducción & Oriente & Norte & Poniente & Sur \\
\hline Mediz Bolio & Ninguna & Habas blancas & $\begin{array}{c}\text { Frijol negro y } \\
\text { haba negra }\end{array}$ & $\begin{array}{l}\text { Frijol de } \\
\text { espalda } \\
\text { amarilla }\end{array}$ \\
\hline $\begin{array}{l}\text { Rivera } \\
\text { Dorado }\end{array}$ & Ninguna & $\begin{array}{l}\text { Frijoles lima } \\
\text { blancos }\end{array}$ & $\begin{array}{l}\text { Frijol negro y } \\
\text { frijoles lima } \\
\text { negros }\end{array}$ & Ninguna \\
\hline Ralph Roys & Ninguna & $\begin{array}{l}\text { "White Lima } \\
\text { Beans" }\end{array}$ & $\begin{array}{c}\text { "Black beans" } \\
\text { and "Black Lima- } \\
\text { beans" }\end{array}$ & $\begin{array}{c}\text { "Yellow-backed } \\
\text { beans" }\end{array}$ \\
\hline $\begin{array}{l}\text { Munro } \\
\text { Edmonson }\end{array}$ & $\begin{array}{l}\text { "Red sapotes } \\
\text { are their Lima } \\
\text { beans" }\end{array}$ & $\begin{array}{l}\text { "White Lima } \\
\text { Beans" }\end{array}$ & $\begin{array}{c}\text { "Black beans" } \\
\text { and "Black Lima- } \\
\text { beans" }\end{array}$ & $\begin{array}{l}\text { "Yellowbacks } \\
\text { are their beans" }\end{array}$ \\
\hline $\begin{array}{l}\text { Richard } \\
\text { Luxton }\end{array}$ & $\begin{array}{l}\text { "Red zapote } \\
\text { tree [their] lima } \\
\text { beans", } \\
\text { "Red fresh } \\
\text { beans" }\end{array}$ & $\begin{array}{l}\text { "White Lima } \\
\text { Beans" }\end{array}$ & $\begin{array}{c}\text { "Black beans" } \\
\text { and "Black Lima- } \\
\text { beans" }\end{array}$ & $\begin{array}{l}\text { "Yellow husk } \\
\text { their town } \\
\text { beans" and } \\
\text { "Yellow the } \\
\text { heart of their } \\
\text { beans" }\end{array}$ \\
\hline
\end{tabular}

${ }^{57}$ Zender, Armijo y Gallegos, 2001: 118-123.

58 Véase al respecto Kaufman, 2003: s. v. Beans, y Dienhart, 1989: s. v. Beans.

${ }^{59}$ García, 2009: 107. 
Además de la omisión de un tipo de frijol en el rumbo Sur en la edición de Rivera Dorado, salta a la vista que ninguna de las tres primeras versiones asocia alguna leguminosa con el Oriente, y que tanto Edmonson como Luxton dicen que los zapotes rojos son los ibes del Este, lo cual, de entrada, es incoherente con la idea de elementos desdoblados del centro a los rumbos.

Las dos traducciones al español son idénticas en el párrafo que habla del Oriente; de hecho, es el único párrafo de los aquí tratados donde no se encuentra discordancia alguna, ni siquiera de matiz. La versión de Roys es similar:

The red flint stone is the stone of the red Mucencab. The red ceiba tree of abundance is his arbor which is set in the east. The red-bullet tree is their tree. The red zapote... The red vine... Reddish are their yellow turkeys. Red toasted $<$ corn $>$ is their corn. ${ }^{60}$

La paleografía de Roys coincide casi en su totalidad con el original:

Chac tok tun u tunil Ah Chac Mucencabe. Chac imix yaxche u Julbal, yan ti lakin. Chacal pucte u cheob. Ix chac ya... ix chac ak bilob. Chac ix kanoulen yulumoob. Ix chac opool yiximob. ${ }^{61}$

Aunque donde puso puntos suspensivos se lee en el original claramente yibillob, algo que omitió, como había señalado Edmonson: "Roys 1967:64 omits ybil(l)ob 'their lima beans'", ${ }^{62}$ y en la siguiente nota apunta que la segunda vez que aparece $Y x$ chac en el párrafo es "Red what is not specified, but there is no gap in the text". ${ }^{63}$ Su paleografía del segmento de las leguminosas del Oriente es $Y x$ chac ya yibillo(b) Yx chac Akbilob Chac yx kan tz'ulob Yulumob: yx chac op'ool Y iximob. ${ }^{64}$ La de Luxton es casi idéntica: Yx chac ya yibillob Yx chac akbilob. ${ }^{65}$

Las traducciones al inglés y al español identifican que la expresión sac ib yibilob (que se encuentra un párrafo adelante) nos habla de habas o frijoles lima blancos, y traducen $e k$ yb yibilob (localizada dos parágrafos abajo) por "habas" o "frijoles lima negros". El escribano tiene lapsus calami recurrentes a lo largo del texto y en el original anotó por separado yi-bilob, las dos veces de los ejemplos anteriores. Si prestamos atención aparece escrito el mismo término bilob en el rumbo Oriente, donde dice yibillob ix chac ak bilob, que en español se tradujo como "Suyos son [...] los bejucos rojos", y al inglés (Roys) como "[...] The red vine [...]". Roys nos dice:

${ }^{60}$ Chilam Balam de Chumayel, 1973: 64.

${ }^{61}$ Ibidem: 15.

62 “Roys 1967: 64 omite Ybil(l)ob ‘sus ibes'”. Chilam Balam de Chumayel, 1986: 104 (la traducción es mía).

63 "Qué es rojo no se específica, pero no existe un salto en el texto". Idem.

${ }^{64}$ Chilam Balam de Chumayel, 1986: 103-104 (la traducción es mía).

${ }^{65}$ Chilam Balam de Chumayel, 1995: 2. 
"chac-ak, the name of an unidentified vine, used medicinally" ${ }^{66}$ es decir, coincide con las versiones en castellano de que es una enredadera, un bejuco o una liana, pues aak' es el vocablo maya que nombra este tipo de plantas.

No obstante lo anterior, existe otra posibilidad, más acorde con el sentido general del texto: que el amanuense haya tenido un lapsus calami en la transcripción omitiendo una "s" y que, como en gran parte del texto, no haya representado gráficamente la vocal larga. Entonces podríamos tener ybilob ${ }^{67}$ ix chac [sá]ak [yi]bi$l o b$. La frase se esclarece a la luz del trabajo de Silvia Terán y Christian Rasmussen, especialistas en la milpa de los mayas peninsulares, quienes, en su libro sobre las plantas factibles de encontrar en ella (1998), listan las variedades de xnuuk iib o ibes de ciclo largo. Entre las variedades que lograron registrar en Xocen está el "Chak sáak de semillas rojas y aplastadas, es como las patitas de la langosta de monte y de sabor agrio", ${ }^{68}$ por lo que considero que el texto no habla de un bejuco sino de un tipo de ibes rojos. Así, esta parte del párrafo del Oriente debería leerse como "sus ibes son los ibes rojos [como patas de langosta]". Esta posibilidad me parece más acorde con el desdoblamiento cuatripartita de los elementos en los rumbos del cosmos.

\section{$Y a$, el zapote yucateco}

El vocablo maya $y a^{\prime}$, que aparece en el Oriente, es traducido en las cinco versiones analizadas como "zapote", lo cual, si bien no es errado, se presta a una imprecisión. En el español mesoamericano, la palabra zapote subsume a diversas frutas, producto de que, en el sistema clasificatorio binario náhuatl de frutas y verduras, tzápot ${ }^{69}$ podía incluir a varias frutas. Francisco Hernández, el protomédico toledano que realizó sus investigaciones en Nueva España entre 1571 y 1576, apuntó en su monumental obra: "Acostumbran los mexicanos, entre quienes florece en toda su propiedad y elegancia la lengua de esta Nueva España, llamar con cierta denominación universal, tzapotl, a todos los frutos de sabor dulce, así como xocotl a todos los de sabor ácido". ${ }^{70}$

Muchas frutas que hoy llamamos "zapotes" son sapotaceae, como el tezontzápotl (Pouteria mammosa) y el tzicotzápotl (Manilkara zapota), aunque puede haber frutos de otros órdenes y familias como el tlilzapotl (Diospyros digyna). Actualmente el vocablo zapote designa en Chiapas y Guatemala a Pouteria mammosa, que es conocida en el resto de México y el Caribe como mamey, palabra de origen arawako; asimismo, la palabra zapote se utiliza en la península de Yucatán para nombrar a

66 "Chac-ak es el nombre de una enredadera, de uso medicinal no identificada", Chilam Balam de Chumayel, 1973: 64 (la traducción al castellano es mía).

${ }^{67}$ El original apunta yibillob, pero debemos suprimir una "l", por tratarse de otro lapsus calami del copista.

68 Terán y Rasmussen, 1998: 135.

69 "Tzapotl. Cierta fruta conocida”, Molina, 2001: f. 152v.

${ }^{70}$ Hernández, 1959: 267. 
Manilkara zapota, que en el resto del país llamamos “chicozapote”. En la taxonomía del idioma maya peninsular existe una clara diferencia entre ja'as (Pouteria mammosa), tauch (Diospyros digyna) y ya' (Manilkara zapota), por lo que la traducción que hacen las cinco versiones, si bien es acertada, es ambigua por las características del vocablo zapote, que designa alrededor de una docena de frutas diferentes. El Calepino de Motul contiene la siguiente entrada que muestra de manera inequívoca la relación entre el vocablo maya ya' y el náhuatl tzicotzápotl: "Ya, niesperos [nísperos] desta tierra que en lengua mexicana se dizen xico capolles [xicoçapotes]". ${ }^{71}$ Por lo anterior sería preferible utilizar el término chicozapote para traducir ya' y no dejar duda sobre a qué fruta se refiere el texto, que, de hecho, es más específico, pues en la taxonomía maya existen dos tipos de chicozapotes: el blanco (sak ya') y el rojo (chak ya'); este último es el que se relaciona con el Oriente. ${ }^{72}$

\section{Una posible traducción}

Asentado lo anterior puedo afirmar que tanto la versión de Mediz Bolio como la de Rivera Dorado están truncas, pues eliminaron del rumbo Sur a un elemento de suma importancia para la vida de los mayas y de los indígenas mesoamericanos en general; cada versión omitió a un elemento central de la dieta indígena, al maíz y al frijol, respectivamente. Asimismo, ninguno de ellos logró, como tampoco las traducciones al inglés, identificar a los ibes del Oriente, asentando en sus versiones que se trataba de un bejuco o de un zapote. Por último, su traducción de $y a$ ' como "zapote" es correcta pero ambigua.

Con todo lo antes dicho y basándome en las traducciones de Roys, Mediz Bolio y Rivera Dorado, pero sobre todo confrontándolas con el original, reitero lo que he propuesto en otro escrito: una posible traducción, más cercana a éste, de los renglones en donde se habla de los rumbos y sus atributos, con el único fin de enmendar las omisiones e identificaciones erróneas, sin alterar de manera general las traducciones ya realizadas:

El pedernal rojo es la sagrada piedra de Ah Chac Mucen Cab. La Madre Ceiba Roja, su Centro Escondido, está en el Oriente. El chacalpucté es el árbol de ellos. Suyos son el chicozapote rojo y los ibes rojos [como patas de langosta]. Los pavos rojos de cresta amarilla son sus pavos. [El grano de maíz] rojo y tostado son sus granos de maíz.

El pedernal blanco es la sagrada piedra del Norte. La Madre Ceiba Blanca es el Centro Invisible de Sac Mucen Cab. Los pavos blancos son sus pavos. Los ibes blancos son sus ibes. El grano de maíz blanco son sus granos de maíz.

El pedernal negro es la piedra del Poniente. La Madre Ceiba Negra es su Centro Escondido. [El grano de maíz] jub [tuxpeño] negro son sus granos de maíz. El camote de pezón negro es su camote. El negro como la noche y pequeño son sus maíces. El frijol negro es su frijol. Los ibes negros son sus ibes.

\footnotetext{
${ }^{71}$ Ciudad Real, 1984: f. 210r (la paleografía es mía).

72 Un bosquejo de este último párrafo lo publiqué en un trabajo previo: Vassallo, 2015: 321.
} 
El pedernal amarillo es la piedra del Sur. La Madre Ceiba Amarilla es su Centro Escondido. El pucté amarillo es su árbol. Amarillo como el pucté es su camote. Amarillas como el pucté son las palomas silvestres que son sus pavos. El maíz amarillo son sus maíces. El frijol de espalda amarilla es su frijol. ${ }^{73}$

\section{¿Quién es la niña blanca?}

Una vez hecha la propuesta anterior, señalo que en las traducciones del Chumayel un elemento fue vaporizado en dos parágrafos en el primer segmento de la Lengua de Zuyua (Zuyua than). ${ }^{74}$ Todas las traducciones de este texto borraron, por una traducción deficiente, a uno de los componentes culturales más importantes de los mayas peninsulares pasados y presentes: el pozol ritual, llamado en maya saka', que si bien está presente de manera clara en el manuscrito que se conserva en la Universidad de Princeton, fue identificado erróneamente como "atole" en las traducciones de este importante texto maya.

La mencionada sección del Chumayel contiene dos series de preguntas, acertijos o adivinanzas. La segunda ronda de éstas consta de 22 elementos que se piden de manera encriptada y en todas las interrogantes se da después la respuesta real de lo requerido en forma metafórica (remitiendo, a mi juicio, a dones que se prescriben como elementos necesarios en una ofrenda), de los cuales solamente tres no son alimentos y bebidas (piedras preciosas, copal y cigarros) ${ }^{75}$ Por otra parte, las bebidas son básicamente hechas con maíz, algunas con cacao y el balché. De los elementos, 21 están en maya y sólo uno (el octavo) está en castellano, ya que en el original se puede leer claramente "pollos", lo que indica que este elemento exógeno ya había sido apropiado por los mayas, pero que aún no se usaba neologismo alguno en lengua maya para nombrarlo. El resto de los elementos se encuentran en maya peninsular. Si de por sí la traducción puede ser compleja, la de términos culinarios puede enredarse aún más. Veamos qué nos dice un experto sobre la especificidad de las taxonomías indígenas y locales respecto a comida y bebida: "[...] las palabras referentes a las comidas es un campo léxico muy amplio, el cual tiene grandes variaciones en cada región o país, no sólo en cuanto al significado adquirido, sino también en relación con los ingredientes o modos de preparar los alimentos". ${ }^{76}$

La investigadora noruega Solveig Anne Hjelleset, que realizó un estudio sobre el léxico de la comida guatemalteca comparándolo con el del resto de América Central, plantea lo difícil de la traducción de términos culinarios. Para ejempli-

\footnotetext{
${ }^{73}$ Idem.

${ }^{74}$ Mediz Bolio (1930) intituló a esta parte del texto "Libro de las pruebas"; Ralph Roys, "The interrogation of the Chiefs" (1973), y Rivera Dorado (2003), "Palabras del Suyua Tan”. Más adelante en el libro existe otra serie de preguntas de Zuyua than.

75 Vale recordar que el humo es considerado alimento de las entidades divinas o sobrenaturales.

76 Quesada, 2002: 143.
} 
ficar lo anterior diserta sobre los variados matices de las albóndigas noruegas, imperceptibles para los que no somos escandinavos, y plantea la dificultad de traducir al español su variedad. Le sorprende que tengamos tal cantidad de comidas y bebidas de maíz con sus variantes, y propone que al estar este grano tan enraizado en la cultura, y al ser de consumo tan amplio, surgen infinidad de términos específicos en nuestro léxico para nombrar los diferentes productos de maíz:

[...] el maíz tiene un lugar especial tanto en la memoria común de la gente como en su alimentación. No es tan curioso que esto se manifieste en el vocabulario, ya que la comunidad linguística nombra las cosas que utiliza, y en este caso la comida que come. Donde se comen muchas comidas de maíz, habrá más necesidad de distinguir léxicamente entre ellas. ${ }^{77}$

Lo mismo aplica para las bebidas preparadas con este grano. En Mesoamérica hay infinidad de ellas: frías, calientes, embriagantes, refrescantes, dulces, saladas, neutras, espesas, ralas, festivas, cotidianas, sacras, profanas... Algunas, como el atole y el pozol, son consideradas comidas más que bebidas, y constituyen parte de la columna vertebral de la alimentación de los pueblos. Ambas pueden, cual deidad mesoamericana, fisionarse en otras tantas y múltiples identidades. En el español corriente del centro de México podemos englobar en "atole" al champurrado y al chileatole, pero quien los haya probado sabe lo diferentes que son entre sí.

Los primeros traductores al castellano de la palabra náhuatl atulli, utilizaron, al igual que las primeras descripciones de españoles, referentes ibéricos como mazamorra, gachas, puchas, poleadas y zahínas. ${ }^{78}$ Más tarde, a finales del siglo xvı, se acuñó el neologismo atole o atol, que era usado indistintamente por los hablantes de castellano, incluso en las mismas regiones geográficas. Dos ejemplos de esto se encuentran en las Relaciones Histórico-Geográficas de la Gobernación de Yucatán:

De los mantenimientos de maíz que antiguamente usaban, y pan, usan ahora de lo mismo, y de beber sus atoles, que es a manera de poleadas, hechos de la masa del maíz molido y deshecho en agua. ${ }^{79}$

${ }^{77}$ Hjelleset, 2010: 82.

${ }^{78}$ El Diccionario de la Real Academia Española (DRAE) define mazamorra como "Comida semejante a las gachas, hecha a base de maíz, y preparada de diversas formas según los lugares de América” (2001: 1472, s. v. "Mazamorra"); gacha: "1. Masa muy blanda que tira a líquida, 3. Plural, Comida compuesta de harina cocida con agua y sal, que se puede aderezar con leche, miel u otro aliño" (ibidem: 1104, s. v. "Gachas"). Puchas, por su parte, es actualmente un arcaísmo que se usa en Castilla para designar lo que se conoce también como "natilla de pobre", ya que no lleva ni leche ni huevos. La palabra actual es puches, que el DRAE define como "Gachas (harina cocida con agua y sal)". Poleadas tiene su étimo en la palabra latina polenta, la definición del Diccionario es idéntica a la de puches: "gachas (harina cocida con agua y sal; ibidem, p. 1856, entradas "Puchas" y "Poleadas"). Zahína es una palabra andaluza de origen árabe, que se define como "Gachas o puches de harina que no se dejan espesar" (ibidem: 2335, s. v. "Zahína”).

${ }^{79}$ Relaciones Histórico-Geográficas de la Gobernación de Yucatán, 1983, t. II: 40. 
El grano con que hacen pan en esta tierra es el que llaman maíz, que en lengua de estos indios llaman yxim, demás de hacerse del pan se hace un brebaje que se llama atol, y en lengua de esta tierra se llama $\left.Z a{ }^{80}\right]$, que es a manera de poleadas. ${ }^{81}$

Una gran variedad de bebidas mesoamericanas elaboradas a base de maíz fueron subsumidas en nuevas palabras del español, que si bien tenían un claro origen en las lenguas americanas no reflejaron a cabalidad las taxonomías indígenas. Surgieron vocablos como atole, pozol, puzunque, tiste, pinolate, tejate, tascalate y chilate. A esto debemos sumar el hecho de que muchas bebidas se siguen elaborando de la misma manera, y otras evolucionaron o desaparecieron, al tiempo que otras tantas fueron creadas.

Durante el siglo xvı, en la península de Yucatán, se utilizó por los españoles el vocablo poçol ("pozol”) para llamar a varias bebidas mayas. No fue sino hasta finales de la centuria siguiente cuando se estandarizó en la región el uso de la palabra que se utiliza actualmente, posole o pozole, para describir a una serie de bebidas de maíz bien diferenciadas en el maya peninsular: saka', k'eyem, puk', akalix y ah tech kela'.

El Calepino de Motul $^{82}$ (siglo xvI) contiene las siguientes entradas relacionadas con bebidas hechas a base de maíz:

Ah the ch cele: poçol y bevida clara sin cacau (f. 30).

Ah the ch cela: idem (f. 30).

Akalix: Bevida hecha de maiz tierno (f. 34).

Ça: atol. Que son gachas puches de masa de maiz /tac uçail venga el atol/de aqui uçail mah: semen mulieris metafhorice (f. $93 \mathrm{v}) .{ }^{83}$

Çaca: ${ }^{84}$ atol. en lengua mexicana, hecho de agua y maiz y bevese frio sin cozer ni calentura, ya entrado el dia: es bevida fresca y sustenta: algunas bezes mezclan cacao en ello (f. 94).

Coppen puchas o atol azedo y sabroso echo de maiz viejo con mezcla de batatas $^{85}$ (f. $82 \mathrm{v}$ ).

Keyem la masa que hazen de maiz molido por despicar (f. 244).

Koyem lo mismo que keyen (f. 250v). ${ }^{86}$

\footnotetext{
${ }^{80}$ Podemos encontrar esta palabra con las grafías ça (así en el original), za y sa (utilizada actualmente).

81 Ibidem: 89.

82 Ciudad Real, 1984.

${ }^{83}$ Como puede observarse, la frase uçail mah ("su atole [de la] vulva”) es traducida al latín con el significado de "Semen de la mujer en sentido metafórico". En las clases de tsotsil, el maestro Miguel Hernández mencionó una metáfora similar en esta lengua: yulil ye mis, que, traducido en forma literal sería "su atole de su boca la vulva" (de ul, "atole", ye, "su boca”, y mis, "vulva”), es "el jugo que le sale a la mujer cuando siente deseo por un hombre". En alguna otra clase lo tradujo simplemente como "flujo".

${ }^{84}$ Con dos “a” pequeñas sobre las “a”.

85 Camotes.

${ }^{86}$ Lapsus calami por keyem, o bien una grafía diferente.
} 
mas ${ }^{87}$ la masa de que se hace el poçol de maiz por espicar, y la masa del atol, y el asiento del mismo atol: y el maiz que se cueze sin cal como para hazer atol (f. 235v). ${ }^{88}$

Si analizamos la lista podemos ver que el Calepino subsume sa y saka' en el recién acuñado neologismo atol. Aunque ambos vocablos pudieran compartir una misma raíz, se trata de bebidas diferentes como se aprecia en otra entrada del mismo diccionario relacionada con el verbo llorar (okol): "okol ça, okol çaca. Llorar porque no le dan atol o poçol" (f. 344v).

Otro de los diccionarios tempranos de español-maya, el Bocabulario de Maya Than, ${ }^{89}$ lista estas otras:

Bevida ordinaria de los indios, de maíz cozido, agua y cacao çaca. ${ }^{90}$

Bevida llamada chocolate chacau haa.

Bevida o poçol de maíz nuebo (para refrescarse) akalix çaca.

Bevida que acen en tiempo de hambre de las espigas de las cañas çaca yijh.

Bevida echa de cacao maíz y pepitas de çapotes tzune (f. 27). ${ }^{91}$

Masa de que hazen el pozol bevida de los indios keyem, koyem.

Masa, por despicar el maíz maว (f. 143v). ${ }^{92}$

Aunque el español subsumió a saka' y k'eyem en pozol o posole, son dos bebidas muy distintas en la taxonomía maya. Un gran etnógrafo, Alfonso Villa Rojas, escribió:

El pozole (keyem) es otra de las bebidas importantes; para hacerlo se cuece ligeramente el maíz en agua con cal y, después, en agua limpia hasta reventar o abrirse; la masa obtenida del grano así cocido se deja agriar por uno o dos días antes de ser usada; para tomarla se disuelve en agua [...] El zacá es la bebida reservada para ofrecer a los dioses y espíritus paganos; se le prepara diluyendo en agua la masa del maíz sin cal. Se le atribuyen propiedades altamente refrescantes..$^{93}$

87 Véase nota 40 sobre el uso de la "c" invertida (0) a principio del período colonial.

${ }^{88}$ Es un homófono del vocablo que designa al pozol en tsotsil y tseltal (mats'). Cabe citar a Brian Stross: "El vocablo protomaya "q'oor ha sido reconstruido como masa de maíz [nixtamal], pero este término no ha pasado consistentemente a las lenguas hijas. "Masa de maíz" ha sido reconstruida para el protomixe como "hïtzi, y para el protozoque como "kït. Una bebida de maíz hecha con la masa del maíz [desleída] en agua fría, ha sido reconstruida para el protomaya como "maatz', pero las lenguas hijas tienen varias palabras diferentes para esta bebida; por ejemplo, en maya yucateco, "k'oyem (del protomaya "q'oor [masa]), en ch'ol, sa', en choltí, sipak, en chuj, pichi', y en ixil, jul. En muchas lenguas mixe-zoqueanas el término para pozol proviene de las palabras del protomixe-zoqueano arriba mencionadas para masa de maíz" (la traducción es mía). Stross, 2006: 582.

${ }^{89}$ Bocabulario de Maya Than, 1993.

${ }^{90}$ Las cinco primeras entradas, idem.

${ }^{91}$ René Acuña señala en la nota 63 de su edición (1993), que esta dicción no está registrada por ningún otro vocabulario maya y resulta de oscuros antecedentes etimológicos. Ibidem, p. 143 (f. 27r).

92 Las dos finales, ibidem: 465 (f. 143v).

93 Villa, 1978: 170. 
Es decir, el k'eyem tiene un empleo cotidiano y profano, mientras el saka' es de uso exclusivamente ritual. Alfonso Dzib, j-men de Xocén, me lo explicó así:

[...] sí, los campesinos utilizan k'eyem, posole, allá en el monte donde se trabaja, en tumbando también, sembrando también, este...., cosechando también, tomando como posole, es mero como para trabajo con la milpa, no es para ofrecido de dios. [...] pero el maíz de saka' es para ceremonias, o sea el monte, para ceremonias de Ch'a' cháak entonces; pero el posole k'eyem es para llevar campesino, pues están preparado gasto para hacer el trabajo en la milpa, cuando se están bien hambre, entonces pues se preparan, se toman. Pero el saka' no, es de material para invocar de los santos Cháak y los santos Balames y también todo lo Me'etan kaax, donde que se trabaja, duende de un monte, duende de la tierra; como tienen cuatro puntos y también como también que te haga un trabajo en el monte, pues entonces te haga este saka' se pone en la mesa, así ande arriba, dos maderitas, se [a]marran dos, este, dos barreras de madera, entonces para preparar la mesa, entonces para hacer invocación, se ponían como este jicaritas chicas, entonces poníamos allá en la mesa, pues le rogaron a Dios, que pidió tu bendición para abrir donde que te van a hacer la tumba, entonces tumbando las maderas, porque hay peligro, tienen víbora, tienen este..., vientos. Pasamos entonces una ocasión que te cae enfermedad, pero antes es mejor que lo este..., rogaron a Dios para que damos poderes, para bendecir un trabajo todos los días, entonces es saka' se necesita para rogar de Dios es bendecido como maíz. Sólo maíz se pone allá en la ollita, y ponga el agua hasta [que] se coce bien. ${ }^{94}$

Podemos ver que ambas sirven para el trabajo del milpero, el físico y espiritual. Aunque similares en sabor y en que se preparan a partir de pellas de masa desleídas en agua, k'eyem y saka' se diferencian (sin tomar en cuenta su uso sacro o cotidiano) en que el primero se bate con agua común y corriente, mientras el segundo con agua proveniente de cenotes especiales, a fin de que sea desleído en "agua virgen". Retomemos otra parte de la plática con Alfonso Dzib: "Pues entonces personas saben donde hay el cenote de Chuyul ha'. Pues te van a buscar un poco para que sirve [para] hacer la ceremonia, para hacer con saka' y para preparar con vino de balche' es esto... necesaria agua de chuyul ha' antigua".

Además, el k'eyem se prepara con maíz nixtamalizado (es decir, cocido con cal), y el saka' solamente con maíz, pues se considera que la cal mata su espíritu o contamina la bebida. Cuando le pregunté qué pasaría si le pusiesen cal, don Alfonso comentó:

[...] ya rebaja el poder, como el poder consagrado de antiguo, no más sólo maíz pide. Entonces van a preparar, ya están listo con masa, van a poner azúcar, van a poner miel, es más bueno endulzado con miel, y para preparar para rogar a Dios, entonces, cuando ya terminamos la ceremonia, $[\ldots]$ puede vas a tomar, ¿sí? Está bueno, está consagrado.

Ahora podemos revisar los dos párrafos del Chumayel donde la presencia de este elemento central de la actividad ritual maya fue identificado de manera erró-

${ }^{94}$ Entrevista del 21 de julio de 2009. 
nea como "atole”. Las traducciones al español de Mediz Bolio y de Rivera Dorado son idénticas y nos hablan de atole, más específicamente de atole chorreado ${ }^{95}$ y no de pozol ritual: “-_Hijo, tráeme tres mitades del cielo. Tengo deseos de comerlas.' '-Así sea padre.' Lo que pide es 'atole chorreado', la espuma del atole. En lenguaje figurado se le pedirá todo”. 96

Las ediciones en inglés ${ }^{97}$ de Roys, Edmonson y Luxton (que cito a continuación en ese orden) tampoco reflejan cabalmente de qué bebida se habla en el original:

"- Son, bring me three segments split from the sky. I desire to eat them." "-Even so, father." This is what he demands, it is atole shaken to a froth, the froth of atole (maize gruel). Everything is asked in the language of Zuyua. ${ }^{98}$

"- Son, go bring me three slices of heaven. I have a desire to eat it." "—-Then it will be so served, father." And what it is that he is asking for is bowls of corn gruel- that is corn gruel foam. In Zuyua language. ${ }^{99}$

"-Son, bring me three layers of heaven; I wish to eat them." "- So be it, father." This is what request: Bowls of atole. That is the foam of atole. Everything is going to be requested in metaphorical speech. ${ }^{100}$

De acuerdo a mi lectura, el original, en su foja 22v, asienta: Mehene, ca a tales ten ox buh caan, yan uol yn hantante: Caybacac be, yume - Hex lic u katice: thohob çacae = lay [y]om çacae = suyua thanil bin katabal tulacal=, por eso considero más acertada la traducción de Barrera Vásquez y Rendón contenida en su reconstrucción de El libro de los libros de Chilam Balam, ya que, como podemos ver en el original no aparecen las palabras mayas para atole ( $s a$ ) o para atole chorreado (tan-chucua'), y sí la palabra saka' más el sufijo demostrativo -e. Es decir, en el párrafo aparece claramente en dos ocasiones saka'e (çacae en el original) y no hay referencia alguna al atole o al atole chorreado. Veamos pues la traducción de Barrera Vásquez y Rendón:

95 En maya peninsular actual se conoce a esta bebida como tan-chucua'.

96 Chilam Balam de Chumayel, 1930: 49 y Chilam Balam de Chumayel, 2003: 86.

97 A lo largo de los siglos los angloparlantes han traducido a su lengua los vocablos españoles atole y pozol como porridge o gruel, que son sus referentes más cercanos. Porridge: A dish consisting of oatmeal or another meal or cereal boiled in water or milk (Oxford Dictionary, 2010: 1383, s. v. "Porridge"). Gruel: A thin liquid food of oatmeal or other meal boiled in milk or water (ibidem: 776, s. v. "Gruel"), pero muchos autores, desde cronistas y viajeros hasta antropólogos y arqueólogos, han considerado poco acertado lo anterior y usan los términos en español atole o pozol. Otros funden a las dos bebidas en una llamándolas atole, pues no perciben el matiz.

No puedo dejar de mencionar que el pirata inglés William Dampier consignó en 1676 un nombre para el posole ("pozol") que era un juego de palabras de los angloparlantes que andaban por las costas mayas: "Si viajan a dos o tres días de casa, llevan consigo en hojas de plátano algo de este maíz molido y un guaje al cinto para hacer su bebida y eso les basta por vitualla, hasta que retornan a casa. Esto es llamado posole y por los ingleses poor-soul" (la traducción es mía). William Dampier, 1699: 113. El juego se da entre el sonido parecido entre pozol y poor-soul, "pobre de espíritu".

${ }^{98}$ Chilam Balam de Chumayel, 1973: 96.

${ }^{99}$ Chilam Balam de Chumayel, 1986: 187.

100 Chilam Balam de Chumayel, 1995: 67. 
“-Hijo mío, trae para mí tres rayas del cielo; tengo deseos de comerlas". "—Así ha de ser, ioh padre!” Lo que pide es el Sacab $\left[{ }^{101}\right]$ Bebida-de-maíz-sin-cal. En el lenguaje de Zuyua se pedirá todo. ${ }^{102}$

Lo único que yo modificaría, y es una cuestión de estilo, es "rayas" del cielo por "partes" del cielo, entendidas como segmentos o divisiones, a más de agregar la presencia de la espuma ${ }^{103}$ en la segunda mención del saka' en el párrafo. Habría que poner una nota explicativa, como lo hicieron Barrera Vásquez y Rendón, a pie de página sobre lo que es esta bebida maya, por lo que el párrafo, según mi propia versión, podría quedar así:

“-Hijo mío, trae para mí tres partes del cielo; tengo deseos de comerlas." "—Así ha de ser, ioh padre!” Lo que pide es el saka' [bebida ritual de maíz], la espuma del saka'. En el lenguaje de Zuyua se pedirá todo.

También fue omitida, en casi todas las traducciones, la presencia innegable del pozol ritual en la segunda vez que se le menciona en esta ronda de preguntas en el texto original. Veamos las traducciones del párrafo (en el siguiente orden: Mediz Bolio, Rivera Dorado, Roys, Edmonson y Luxton):

"-Hijo tráeme tu orina de niño para que yo la vea y a la que tiene blanca y limpia la cara, la muy bonita; blanco es su rebozo y su cinturón. Tengo muchos deseos de ella." "-Así sea Padre." He aquí lo que pide: la jícara blanca y atole. Lenguaje figurado. ${ }^{104}$

"-Hijo tráeme a tu hija para que yo la vea y a la que tiene blanca y limpia la cara, la muy bonita; blanco es su rebozo y su cinturón. Tengo muchos deseos de ella." “-Así sea Padre." He aquí lo que pide: la jícara blanca y atole. Lenguaje figurado. ${ }^{105}$

"-Son, bring me your daughter that I may see her. Pale is her face and very beautiful. White are her head-covering and her sash. I greatly desire her." "-Tilt is well, father." What he asks for is a white calabash cup < filled $>$ with atole. The language of Zuyua. ${ }^{106}$

${ }^{101}$ La palabra saka' tiene varias grafías: çaca, zacah, sacah, saca, saca', zaca, zaca', saka, saka', sacab. Sobre su etimología, que por lo demás parece bastante clara, conviene citar al propio Alfredo Barrera Vázquez: "En el actual lenguaje maya yucateco sak significa blanco, considerándolo como un morfema libre... en algunos vocablos complejos como zacá, especie de atole, compuesto de sak $+a$, donde $a$ ' es lo mismo que $h a$ ' agua, resultando pues, que zacá quiere decir 'agua blanca', pero significa atole" (1941: 76-78. Barrera Vásquez, como otros tantos estudiosos, subsume saka' en atole; mas en la traducción de El libro de los libros asentó, diferenciándolos, "Bebida-de-maíz-sin-cal".

102 Barrera y Rendón, 1998: 140.

103 Actualmente hay dos tipos de saka': el blanco (mayoritario) y el que se adereza con cacao (que era más común en tiempos pasados). En ninguno de los dos casos se le saca espuma, pero esto no quiere decir que antiguamente no se hiciese. Debemos recordar el papel tan importante de la espuma en las bebidas elaboradas o aderezadas con cacao.

104 Chilam Balam de Chumayel, 1930: 50.

105 Chilam Balam de Chumayel, 2003: 88.

106 Chilam Balam de Chumayel, 1973: 97. 
"-Son, go bring me your daughter for me to see. Have her face wrapped all in white. She is very beautiful. Brilliant white is her shawl and her sash. I very much want some." "- It shall be served, father." And what it is that he is asking for is a white bowl is chicken in corn gruel. Zuyua. ${ }^{107}$

"-Son, go and bring your daughter for me to see; that is her face shrouded in pure white, very beautiful, her shawl pure white and her sash. I desire her greatly." "-So be it, father." And so what he request [Is] a white gourd bowl and chicken in maize sauce. Metaphor. ${ }^{108}$

De nuevo me parece más certera la versión de Barrera y Rendón:

"-Hijo mío, tráeme a tu niña, la del albo rostro, para que yo la vea, la de bella toca blanca, la de moño anudado, tengo deseos de ella." “-Así ha de ser, ioh padre!" Lo que pide es la jícara blanca llena de Sacab, Agua-de-maíz-sin-cal. Habla es de Zuyua. ${ }^{109}$

Pero esta traducción omite también la presencia del tzune, que se encuentra ligada a la del saka'. Veamos qué consigna el texto original, de acuerdo a mi paleografía: Mehene, ca a tales ten - a uix mehen: yn uilab - lay hach çac haJen u uiche: hach cichpame $=$ çaçac $u$ booch $=y$ [etel] $u$ kaxi= Hach yan uol ti: caybacac, yume= hex lic u katice $=$ sac luch $=y$ letel] tzune çacae $=$ Suyua- $\left(\right.$ foja 23r). ${ }^{110}$ El texto apunta claramente tzune çacae. Vale la pena recordar que el Bocabulario de maya than define tzune como: "Bevida echa de cacao maíz y pepitas de çapotes". Para arrojar luz sobre el origen del vocablo, ${ }^{111}$ tenemos que recurrir a una fuente del centro de México, que nos señala que tzune es un préstamo del náhuatl al maya: "Otra bebida llamada tzone se prepara con grano indio ${ }^{112}$ y cacahoatl tostados en partes iguales y cocidos luego con una pequeña cantidad del mismo grano ablandado, y sirve como alimento refrescante, no como medicina". ${ }^{113}$ Este extracto proviene de la descripción del cacao de Francisco Hernández, y el tzone mencionado es lo mismo que el tzune (recordemos que $o$ y $u$ son alófonos en náhuatl).

Sería muy extenso hablar sobre las bebidas mesoamericanas, donde se combinan maíz, cacao y sapoyul, ${ }^{114}$ baste decir que las hay sacras y profanas. Estas

107 Chilam Balam de Chumayel, 1986: 190.

108 Chilam Balam de Chumayel, 1995: 71.

109 Barrera y Rendón, 1998: 142.

110 En dos ocasiones desenlacé la abreviatura consistente en una y herida, que era la convención colonial para la palabra yetel (el Motul la define como "conjunción copulativa”).

111 Rene Acuña nos dice que esta dicción no es registrada por ningún otro vocabulario maya y es de oscuros antecedentes etimológicos. Véase al respecto la nota 63 del Bocabulario de Maya Than, 1993: 143.

112 Manera arcaica de llamar al maíz en castellano.

113 Hernández, 1959: 305.

114 Sapoyul es una manera de denominar al hueso de mamey (Pouteria mammosa). Entre estas bebidas se encuentran el tejate de Oaxaca, el amuchit choltí, los pozoles de pixte del Sur de Veracruz y Tabasco, el batido guatemalteco, el atole de suchile del mismo país y el ach tec cela maya. 
bebidas son de suma importancia en la actualidad, por lo que no es sorprendente que este párrafo del Chumayel nos hable de que se está pidiendo saka'-tzune en una jícara blanca. Para el Yucatán colonial hay dos bebidas similares y con los mismos ingredientes (maíz, cacao y sapayul) que se diferenciaban, así como el pozol cotidiano ( $k$ 'eyem) y el ritual (saka'), por su uso profano o sacro: éstas eran el ah the ch cele, bebida refrescante de uso común, y el tzune, de uso ritual. Es este último el que se pide asociado al saka' en este parágrafo del Chumayel. Ambos elementos fueron borrados en las traducciones y me parece importante restituir su presencia.

Este trabajo fue impulsado, en última instancia, por lo que atinadamente escribió Mercedes de la Garza:

Esperamos que, como lo desearon los antiguos mayas de Chumayel, su libro sagrado se siga manteniendo vivo. Que sean escuchadas sus palabras, reveladoras del ser del hombre maya y de su afán de conservar la identidad y la dignidad, atropelladas por los conquistadores y por muchos otros desde entonces. Esperamos que esas palabras comuniquen algo de su significación profunda, algo que tenga sentido hoy $[. . .]^{115}$

Así pues confío en que este pequeño aporte motive a realizar las mejoras necesarias para que en esta época en que se aproxima el "tiempo de la vuelta", las "palabras de significación profunda" sean en las traducciones lo más fieles posibles al Chumayel original, a fin de que podamos disfrutarlo, estudiarlo y darle sentido pleno.

115 Chilam Balam de Chumayel, 1985: 18. 


\section{BIBLIOGRAFÍA}

Barrera Vásquez, Alfredo

1934 "Una versión inglesa del Chilam Balam de Chumayel", Boletín del Museo Nacional de Arqueología, Historia y Etnografía, 6a época, tomo I: 55-68.

1941 "La significación de los morfemas zac [sak] y chiic [ciilk] en los nombres sacbé y sacchic ('sensontle')", Los mayas antiguos: monografías de arqueología, etnografía y lingüística mayas, publicadas con motivo del centenario de la exploración de Yucatán por John L. Stephens y Frederick Catherwood en los años 1841-42, pp. 76-78, César Lizardi Ramos (ed.). México: El Colegio de México.

Barrera Vásquez, Alfredo y Silvia Rendón

1998 El libro de los libros de Chilam Balam. México: Fondo de Cultura Económica.

Baudoin, Jean-Pierre et al.

2004 Ecogeography, Demography, Diversity and Conservation of Phaseolus lunatus. Roma: International Plant Genetic Resources Institute (Systematic and Ecogeographic Studies on Crop Genepools, 12).

Bocabulario de Maya Than

1993 René Acuña (ed.). México: Universidad Nacional Autónoma de México, Instituto de Investigaciones Filológicas, Centro de Estudios Mayas (Serie Fuentes para el Estudio de la Cultura Maya, 10).

Bolles, David

1984 "Munro S. Edmonson. The Ancient Future of the Itzá (1982): A Translation of the Book of Chilam Balam of Tizimin", Anales de Antropología, 21 (1): 337-341.

Ciudad Real, fray Antonio de

1976 Tratado curioso y docto de las grandezas de la Nueva España. Relación breve y verdadera de algunas cosas de las muchas que sucedieron al padre fray Alonso Ponce en las provincias de la Nueva España siendo comisario general de aquellas partes, Josefina García Quintana y Víctor Manuel Castillo Farreras (ed. crít.). México: Universidad Nacional Autónoma de México, Instituto de Investigaciones Históricas.

1984 Calepino de Motul, René Acuña (ed.). México: Universidad Nacional Autónoma de México, Instituto de Investigaciones Filológicas, Centro de Estudios Mayas.

2001 Calepino de Motul, René Acuña (ed.). México: Plaza y Valdés.

Chilam Balam de Chumayel

Vid. anexo.

Dampier, William

1699 Voyages and descriptions: In three parts, vol. II: Two voyages to Campeachy, with a description of the coasts, product, inhabitants, logwood-cutting, trade, etc. of Jucatan, Campeachy, New-Spain, etc. London: Botham for James Knapton.

De la Garza, Mercedes (ed.)

1980 Literatura maya. Caracas: Biblioteca Ayacucho. 
Diccionario de la Real Academia de la Lengua Española

2014 Madrid: Real Academia Española, <www.rae.es>.

Dienhart, John Michael

1989 The Mayan Languages. A Comparative Vocabulary. Odense: University Press of Southern Denmark.

García Barrios, Ana

2009 “Chaahk y el Pájaro O’ en el período Clásico y en narraciones coloniales”, Estudios de Cultura Maya, XXXIV: 93-114.

Hanks, William F.

1988 "Grammar, Style, and Meaning in a Maya Manuscript", International Journal of American Linguistics, 54 (3): 331-364.

Hernández, Francisco

1959 Historia natural de la Nueva España. México: Universidad Nacional Autónoma de México (Obras completas, vol. II).

Hjelleset, Solveig Anne

2010 "El léxico de la comida en Guatemala. Análisis geolinguíístico", tesis de Maestría en Español y Estudios Latinoamericanos. Bergen: Universidad de Bergen, Departamento de Español y Estudios Latinoamericanos.

Kaufman, Terrence

2003 Preliminary Mayan Etymological Dictionary. Foundation for the Advancement of Mesoamerican Studies Inc., <www. famsi.org/reports/ 01051/pmed.pdf>.

Mediz Bolio, Antonio

1970 "El maya y el maíz”, Ocho ensayos mayistas, pp. 62-67. Mérida: Gobierno del Estado de Yucatán.

Molina, fray Alonso de

2001 Vocabulario en lengua castellana-mexicana, mexicana-castellana. México: Porrúa.

Montes de Oca, Mercedes

2005 "Niokculida, Timahe, K'eojetik, Huehuetlahtolli, Telapnaawe: la tradición oral de los pueblos nativos de México y Norteamérica”, Acta Poetica, 26 (1-2): 547576.

Oxford Dictionary

2010 Oxford: Oxford University Press.

Quesada Pacheco, Miguel Ángel

2002 El español de América. San José: Editorial Tecnológica de Costa Rica.

Relaciones Histórico-Geográficas de la Gobernación de Yucatán

1983 Mercedes de la Garza, Martha Ilia Nájera, María del Carmen León Cázares y Tolita Figueroa (eds.), María del Carmen León Cázares (pal.). México: Univer- 
sidad Nacional Autónoma de México, Instituto de Investigaciones Filológicas, Centro de Estudios Mayas (Fuentes para el Estudio de la Cultura Maya, 1 y 2).

Ritual de los Bacabes

2007 Ramón Arzápalo (ed.). Mérida: Universidad Nacional Autónoma de México, Centro Peninsular en Humanidades y en Ciencias Sociales, Universidad Autónoma de Yucatán y Ayuntamiento de Mérida.

Siméon, Rémi

2002 Diccionario de la lengua náhuatl o mexicana. México: Editorial Siglo XXI.

Sotelo Santos, Laura Elena

2002 Los dioses del Códice Madrid. México: Universidad Nacional Autónoma de México, Instituto de Investigaciones Filológicas y Facultad de Filosofía y Letras.

Stross, Brian

2006 "Maize in Word and Image in Southern Mesoamerica", Histories of Maize: Multidisciplinary Approaches to the Prehistory, Linguistics, Biogeography, Domestication, and Evolution of Maize (Zea Mays L.), pp. 578-597, John E. Staller, Robert H. Tykot y Bruce F. Benz (eds.). Nueva York: Elsevier Publishers.

Suárez Molina, Víctor

2013 Voces mayas y mayismos en el español de Yucatán. Yucatán: Universidad Autónoma de Yucatán, <http://www.mayas.uady.mx/ artículos/voces.html>.

Terán, Silvia y Christian Rasmussen

1998 Las plantas de la milpa entre los mayas. Mérida, México: Fundación Tun Ben Kin.

Thompson, Eric S.

2008 Historia y religión de los mayas. México: Editorial Siglo XXI.

Vassallo, Miguel

2012 "La creación del Centro Inocente: La iniciación chamánica de doña Lupe Cohuo (Extractos hilados de diarios de campo)", Estudios Mesoamericanos, nueva época, año 7 (13): 87-97.

2015 "Los maíces amarillos, los ibes rojos y el chicozapote. Omisiones e identificaciones erróneas en diversas ediciones de la primera página del Chilam Balam de Chumayel", Anales de Antropología, 49 (2): 317-322.

Villa Rojas, Alfonso

1978 Los elegidos de Dios. Etnografía de los mayas de Quintana Roo. México: Instituto Nacional Indigenista.

Zender, Marc, Ricardo Armijo y Miriam Judith Gallegos

2001 "Vida y obra de Ah Pakal Tahn, un sacerdote del siglo vill en Comalcalco, Tabasco, México", Los investigadores de la cultura maya, vol. 9, t. II, pp. 118123. México: Universidad Autónoma de Campeche, Centro de Investigaciones Históricas y Sociales. 


\section{ANEXO: PRINCIPALES EDICIONES DEL CHILAM BALAM DE CHUMAYEL (EN ORDEN CRONOLÓGICO)}

The Book of Chilam Balam of Chumayel

1913 George B. Gordon (ed.). Philadelphia: University Museum of Pennsilvania.

El libro de Chilam Balam de Chumayel

1930 Antonio Mediz Bolio (versión del maya). San José: Imprenta y Librería Lehman (Ediciones del Repertorio Americano).

1941 Antonio Mediz Bolio (trad. y pról.). México: Universidad Nacional Autónoma de México (2a ed., 1952; 3a ed., 1973).

Livre de Chilam Balam de Chumayel

1955 Benjamín Péret (trad. del esp.). Paris: Denoël.

The Book of Chilam Balam of Chumayel

1973 Ralph L. Roys (trad. del maya al inglés). Oklahoma City: University of Oklahoma Press.

Les prophéties du Chilam Balam

1976 Jean Marie Le Clézio (trad. y pról.). París: Gallimard.

Chilam Balam de Chumayel

1985 Mercedes de la Garza (pról., introd. y notas). México: Secretaría de Educación Pública (Cien de México) (2ª ed., 2006).

Heaven Born Merida and Its Destiny: The Book of Chilam Balam of Chumayel

1986 Munro Edmonson (Translated and annotated by...). Austin: University of Texas Press.

The Book of Chumayel. The Counsel Book of the Yucatec Maya (1539-1638).

1995 Richard N. Luxton (Translated by...). Laguna Hills: Aegean.

Libro de Chilam Balam de Chumayel

2003 Miguel Rivera Dorado (pról.). Madrid: Dastin (Crónicas de América).

Los libros de Chilam Balam de Chumayel

2008 Coral Pérez (introd.). Caracas: Fundación Editorial El Perro y la Rana (Los Ríos Profundos). 